and modified baseline observation carried forward for continuous data. Safety data were analyzed for all patients who received $\geq 1$ dose of IXE.

Table 1. Demographic and efficacy results for patients continuously treated with IXE for 116 weeks

\begin{tabular}{lllll}
\hline & IXE Q4W N=157 & \multicolumn{2}{l}{ IXE Q2W N=195 } \\
\hline Demographics & & & \\
\hline Age & $42.7(13.0)$ & & $41.8(11.2)$ & \\
Male (n, [\%]) & $124(79.0)$ & & $132(67.7)$ & \\
Baseline ASDAS & $3.92(0.80)$ & & $3.95(0.76)$ & \\
Baseline BASDAI & $7.07(1.26)$ & & $6.74(1.86)$ & \\
Baseline BASFI & $6.57(1.76)$ & & $3.97(1.52)$ & \\
Baseline BASMI & $4.08(1.46)$ & & $33.26(6.88)$ & \\
Baseline SF-36 PCS & $33.90(7.27)$ & & & \\
Outcome measure & & & & \\
Response (n, [\%]) & Week 52 & Week 116 & Week 52 & Week 116 \\
ASDAS <2.1 & $75(47.8)$ & $69(43.9)$ & $88(45.1)$ & $96(49.2)$ \\
ASAS partial remission & $34(21.7)$ & $31(19.7)$ & $35(17.9)$ & $39(20.0)$ \\
ASAS40 & $82(52.2)$ & $89(56.7)$ & $99(50.8)$ & $108(55.4)$ \\
BASDAI50 & $78(49.7)$ & $75(47.8)$ & $83(42.6)$ & $99(50.8)$ \\
Change from baseline & & & & \\
ASDAS & $-1.64(1.05)$ & $-1.60(1.15)$ & $-1.63(1.03)$ & $-1.78(1.04)$ \\
BASFI & $-2.88(2.31)$ & $-2.76(2.39)$ & $-2.83(2.38)$ & $-3.15(2.34)$ \\
BASMI & $-0.57(0.95)$ & $-0.57(0.93)$ & $-0.53(0.92)$ & $-0.60(1.00)$ \\
SF-36 PCS & $9.03(8.62)$ & $8.43(8.70)$ & $8.87(7.57)$ & $9.86(8.45)$ \\
\end{tabular}

Data are mean (SD) unless otherwise noted. Non-responder imputation was used for categorical variables, and modified baseline observation carried forward for continuous variables.

Results: Of the 773 patients enrolled in COAST-Y, $86.0 \%$ completed Week 116 of treatment (52 weeks of one of the originating trials and 64 weeks of COAST-Y). Among the patients continuously treated with IXE for 116 weeks (IXE Q4W: $\mathrm{N}=157$; IXE Q2W: $\mathrm{N}=195)$, 46.9\% achieved low disease activity (ASDAS <2.1), and $19.9 \%$ achieved ASAS partial remission at 116 weeks (Table 1; Figure 1). In comparison to baseline, $56.0 \%$ achieved ASAS40 (Table 1). The mean change from baseline at Week 116 was -1.70 for ASDAS, -2.98 for BASFI, and 9.22 for SF-36 Physical Component Summary (Table 1). Similar observed responses were achieved between the patients continuously treated with IXE and patients initially treated with placebo or adalimumab. For the 932 patients in the safety population, no new safety signals were identified.

Conclusion: Ixekizumab treatment led to consistent and sustained long-term improvements in disease activity and quality of life in patients with r- and nr-ax$\mathrm{SpA}$, with no new safety signals after up to 2 years of treatment.

REFERENCES:

[1] Dougados, et al. Ann Rheum Dis 2020;79:176-185.

[2] Deodhar, et al. Lancet 2020; 395:53-64.

Figure: ASDAS $<2.1$ responses for patients continuously treated with IXE for 116 weeks

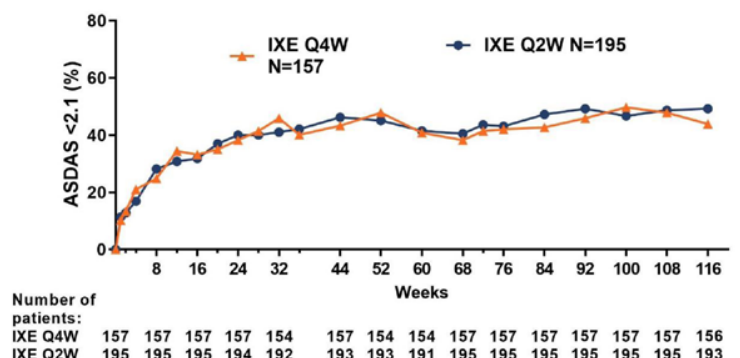

Non-responder imputation was used for ASDAS $<2.1$

Abbreviations (Table and Figure): ASAS40=achieving $40 \%$ improvement in Assessment of SpondyloArthritis International Society (ASAS) criteria, ASDAS=Ankylosing Spondylitis Disease Activity Score; BASDA150=achievin $50 \%$ improvement in Bath Ankylosing Spondylitis Disease Activity Index; BASFI=Bath Ankylosing Spondylitis Functional Index; $B$ BSMM = Bath Ankylosing Spondylitis Metrology Index; IXE=ixekizumab; $Q 2$ W=every 2
Q4W=every 4 weeks; SF-36 PCS=36-item Short-Form Health Survey Physical Component Summary.

Disclosure of Interests: Juergen Braun Speakers bureau: Abbvie, Amgen, BMS, Boehringer, Celgene, Celltrion, Centocor, Chugai, Eli Lilly and Company, Medac, MSD, Mundipharma, Novartis, Pfizer, Roche, Sanofi-Aventis, and UCB, Consultant of: Abbvie, Amgen, BMS, Boehringer, Celgene, Celltrion, Centocor, Chugai, Eli Lilly and Company, Medac, MSD, Mundipharma, Novartis, Pfizer, Roche, Sanofi-Aventis, and UCB, Grant/research support from: Abbvie, Amgen, BMS, Boehringer, Celgene, Celltrion, Centocor, Chugai, Eli Lilly and Company, Medac, MSD, Mundipharma, Novartis, Pfizer, Roche, Sanofi-Aventis, and UCB, Uta Kiltz Speakers bureau: AbbVie, Hexal, MSD, Novartis, Pfizer, Roche, and UCB, Consultant of: AbbVie, Biocad, Eli Lilly and Company, Grünenthal, Hexal, Janssen, Novartis, Pfizer, and UCB, Grant/research support from: AbbVie, Amgen, Biogen, Hexal, Novartis, and Pfizer, Atul Deodhar Consultant of: AbbVie, Amgen, Boehringer Ingelheim, Bristol Myers Squibb, Celgene, Eli Lilly and Company, Giliad, GlaxoSmith \& Kline, Janssen, Novartis, Pfizer, and UCB, Grant/research support from: AbbVie, Boehringer Ingelheim, Eli Lilly and Company, GlaxoSmith \& Kline, Novartis, Pfizer, and UCB, Tetsuya Tomita Speakers bureau: AbbVie, Astellas, Bristol-Myers Squibb, Eisai, Eli Lilly and Company, Janssen, Mitsubishi Tanabe, Novartis, Takeda, Pfizer, Consultant of: AbbVie Astellas, Bristol-Myers Squibb, Eisai, Eli Lilly and Company, Janssen, Mitsubishi Tanabe, Novartis, Takeda, Pfizer, Maxime Dougados Consultant of: AbbVie, BMS, Eli Lilly and Company, Merck, Novartis, Pfizer, Roche, and UCB, Grant/ research support from: AbbVie, BMS, Eli Lilly and Company, Merck, Novartis, Pfizer, Roche, and UCB, Rebecca Bolce Shareholder of: Eli Lilly and Company, Employee of: Eli Lilly and Company, David Sandoval Shareholder of: Eli Lilly and Company, Employee of: Eli Lilly and Company, David Adams Shareholder of: Eli Lilly and Company, Employee of: Eli Lilly and Company, Chen-Yen Lin Shareholder of: Eli Lilly and Company, Employee of: Eli Lilly and Company, Jessica A. Walsh Consultant of: AbbVie, Amgen, Eli Lilly and Company, Novartis, Pfizer, and UCB, Grant/research support from: AbbVie, Merck, and Pfizer DOI: 10.1136/annrheumdis-2021-eular.1124

\section{POS0913 UVEAL CATARACT IN PATIENTS WITH SPONDYLOARTHRITIS AND OTHER IMMUNO- INFLAMMATORY DISEASES AND ITS SURGICAL TREATMENT}

S. Avetisov ${ }^{1,2}$, I. Razumova ${ }^{3}$, K. Avetisov ${ }^{4}$, A. Godzenko ${ }^{5} .{ }^{1}$ Federal State Budgetary Scientific Institution Research Institute of Eye Diseases, Chief Scientific Adviser, Moscow, Russian Federation; ${ }^{2}$ I.M. Sechenov First Moscow State Medical University (Sechenov University), Department of Eye Diseases, Moscow, Russian Federation; ${ }^{3}$ Federal State Budgetary Scientific Institution Research Institute of Eye Diseases, Retinal and Optic Nerve Pathologies, Moscow, Russian Federation; ${ }^{4}$ Federal State Budgetary Scientific Institution Research Institute of Eye Diseases, Department of Modern Methods of Treatment, Moscow, Russian Federation; ${ }^{5}$ Federal State Budgetary Educational Institution of Additional Professional EducationRussian Medical Academy of Continuous Professional Education, Rheumatology, Moscow, Russian Federation

Background: Uveitis is a common extra-skeletal manifestation of various sys temic diseases, in particular, spondyloarthritis (SpA). Uveal cataract is the frequent complication of endogenous uveitis. Surgical treatment of uveal cataracts is associated with certain problems, the main being a potential risk of recurrence of uveitis, especially in the case of intraocular lens (IOL) implantation.

Objectives: To analyse the results of surgery of complicated uveal cataract in patients with $\mathrm{SpA}$ and other rheumatic disorders.

Methods: 30 pts (34 eyes) with uveal cataract as a result of systemic immuno-inflammatory diseases were assessed in the "Research Institute of Eye Diseases" in the period from 2006 to 2018 . The postoperative follow-up period ranged from 2 to 12 years. 20 pts had different variants of SpA (Group 1):7 (7 eyes) - ankylosing spondylitis, 1 (1 eye) -reactive arthritis, 1 (1 eye) - psoriatic arthritis, 4 (6 eyes) - juvenile spondyloarthritis, 8 (8 eyes) non-radiological SpA. 10 patients (11 eyes) had other systemic diseases (Group 2): 1 (1 eye) Behcet's disease 1 (1 eye) - multiple sclerosis, 3 (3 eyes) - Fuchs heterochromic cyclitis, 2 (2 eyes) -cutaneous psoriasis, and 3 ( 4 eyes) -uveitis of unknown etiology. 4 pts (6 eyes) with juvenile arthritis and pronounced corneal ribbon degeneration were underwent standard intracapsular cryoextraction of the cataract, followed by optical correction of aphakia using spectacle lenses. In other cases, ultrasound phacoemulsification with IOL implantation was used as a surgical aid. All patients had a period of uveitis remission before opreation for at least 2 months.Anti-inflammatory therapy using local glucocorticoid and local and systemic nonsteroidal antiinflammatory drugs was prescribed 2 weeks before and within a month after the operation. Intra and postoperative complications, fluctuations in intraoc ular pressure (IOP), improvement of visual acuity, and the frequency of uveitis flares after surgery were assessed as the main criteria for analyzing the results of surgery.

Results: A statistically significant decrease in the number of uveitis exacerbations was observed in all pts: in group 1 - from $2,5 \pm 0,65$ to $1,2 \pm 0,65$ per year $(p<0.0001)$, in group 2 - from $2,55 \pm 0,21$ to $0,89 \pm 0,21$ per year $(p<0.0001)$, while there were no statistically significant differences between the groups $(p=0.31)$ Statistically significant increase in maximum visual acuity was observed in all groups: in group 1 - from $0,2 \pm 0,38$ to $0,58 \pm 0,74, p<0.0001$, in group $2-$ from $0,24 \pm 0,05$ to $0,69 \pm 0,07, p<0.0001$. No complications were observed during operations. The phenomena of bullous keratopathy after intracapsular extraction were noted in 2 pts with juvenile arthritis and ribbon-like corneal degeneration. No progression of corneal changes was observed. Opacity in the central zone of the posterior capsule in the period from 2 to 24 months after surgery occurred in 7 cases. In all cases, laser dissection of the posterior lens capsule was performed. Transient increase in IOP in the early postoperative period, normalized by local hypotensive therapy, occurred in 8 cases in groups I. In the long- term follow-up period (2-24 months), persistent IOP decompensation occurred in 6 
cases in groups 1 and in 3 cases in groups 2 , which required various types of anti-glaucoma operations. Cystic macular edema developed in one case 5 months after surgery as a result of uveitis exacerbation and was stopped by corticosteroid therapy.

Conclusion: Surgery of uveal cataracts in pts with SpA and other immuno-inflammatory diseases providing adequate pre- and postoperative anti-inflammatory therapy improves visual acuity and reduces the frequency of uveitis relapses. Monitoring of IOP is necessary in the postoperative period.

REFERENCES:

[1] Mora P., Gonzales S., Ghirardini S. et al. Perioperative prophylaxis to prevent recurrence following cataract surgery in uveitis patients a two-centre, prospective, randomized trial. Acta Ophthalmol. Scandinavica Fondation. 2016 Sept.; 94(6): e 390-394. http//doi. 10.1111/aos.12955. Epub 2016 Feb 5.

Disclosure of Interests: None declared

DOI: 10.1136/annrheumdis-2021-eular.1193

\section{POS0914 IS THERE AN ASSOCIATION BETWEEN AUTOANTIBODIES INDUCTION AND LOSS OF THERAPEUTIC EFFICACY IN PATIENTS WITH AXIAL SPONDYLOARTHRITIS AND PSORIATIC ARTHRITIS TREATED WITH ANTI-TNF- $\alpha$ AGENTS?}

A. Martins ${ }^{1}$, D. Santos Oliveira ${ }^{1}, 2$, F. R. Martins ${ }^{3}$, M. Rato ${ }^{1}$, F. Oliveira Pinheiro ${ }^{1}$ D. Fonseca ${ }^{4}$, B. M. Fernandes ${ }^{1}$, S. Garcia ${ }^{1}$, S. Pimenta ${ }^{1,5}$, M. Bernardes $^{1,5}$, L. Costa ${ }^{1}{ }^{1}$ Centro Hospitalar Universitário São João, Rheumatology, Porto, Portugal; ${ }^{2}$ Faculdade de Medicina da Universidade do Porto - FMUP, Center for Health Technology and Services Research (CINTESIS), Porto, Portugal; ${ }^{3}$ University Hospital Center of Algarve, Rheumatology, Faro, Portugal; ${ }^{4}$ Centro Hospitalar Vila Nova de Gaia / Espinho - Unit 1, Rheumatology, Vila Nova de Gaia, Portugal; ${ }^{5}$ Faculdade de Medicina da Universidade do Porto - FMUP, Rheumatology, Porto, Portugal

Background: Induction of autoantibodies is frequently observed in patients treated with a TNF- $\alpha$ blocker. According to other authors, the incidence of induction of antinuclear antibodies (ANA) and anti-double stranded DNA antibodies (anti-dsDNA) varies between $23-57 \%$ and $9-33 \%$, respectively. However, it is unknown whether the induction of these autoantibodies affects the pharmacokinetics and bioavailability of biotherapy and, consequently, reduces the efficacy and safety of the drug.

Objectives: To analyze if there is an association between autoantibodies induc tion and therapeutic efficacy in a monocentric cohort of patients with axial spondyloarthritis (axSpA) and psoriatic arthritis (PsA) treated with anti-TNF- $\alpha$ agents Methods: The authors performed a retrospective analysis of patients with axSpA and PsA treated in our University Hospital with a TNF- $\alpha$ blocker as first biologic agent, and analysed the autoantibodies induction rate after 12 (T12) and 24 (T24) months of therapy. Then, they investigated the influence of autoantibodies in therapeutic efficacy at T12 and T24. Clinical evaluation, laboratory findings including erythrocyte sedimentation rate (ESR) and C-reactive protein (CRP) and disease activity and functional scores (Bath Ankylosing Spondylitis Disease Activity Index - BASDAI, AS Disease Activity Score with CPR - ASDAS-CRP, Bath AS Functional Index - BASFI) were collected from reuma.pt and medica records. For PsA patients, Disease Activity Score-28-CRP (DAS28-CRP), Simple Disease Activity Index (SDAI), Clinical Disease Activity Index (CDAI) and Health Assessment Questionnaire (HAQ) scores were also collected. Patients with positive ANA (titer $>1 / 100$ ) prior to anti-TNF- $\alpha$ therapy were excluded. Continuous variables were analyzed using a t-test and categorical variables using a Chisquare test. $P$-value $<0.05$ was considered statistically significant.

Results: In the axSpA group, 235 patients were included, 44.5\% were females, mean age at diagnosis of $42.3 \pm 12.4$ years and median disease duration of 11.5 (IQR 6.0-21.0) years. Positive ANA were observed in $16.9 \%$ at T12 and $26.3 \%$ at T24 and positive anti-dsDNA in $3.4 \%$ at $\mathrm{T} 12$ and $3.8 \%$ at T24, with similar conversion rates between different anti-TNF drugs and no significant gender difference. A significant difference in ASDAS-CPR was found in axSpA patients with and without ANA at T12 ( $p=0.047)$. ASDAS-CPR was 1.16 times higher in patients with ANA comparing to patients without them. However, no difference was found in the others disease activity and functional scores at T12. Furthermore, no significant difference, including ASDAS-CPR, was found at T24. Also, there was no significant difference found when comparing patients with and without anti-dsDNA. In the PsA group, 94 patients were included, 46.8\% were females, mean age at diagnosis of $46.7 \pm 11.7$ years and median disease duration of 11.5 (IQR 6.5-16.5) years. Positive ANA were found in $14.9 \%$ at T12 and $21.3 \%$ at T24 and positive anti-dsDNA in $2.1 \%$ at T12 and $3.2 \%$ at T24. When comparing the groups with and without ANA and with and without anti-dsDNA at T12 and T24, no significant difference in disease activity and functional scores was found.

Conclusion: This study revealed high rates of serology conversion, similar to the rates described before. The authors found that ASDAS-CPR was higher in axSpA patients with ANA after 12 months of therapy. However, this difference was no longer evident after 24 months. No other significant difference was found between patients with and without ANA or with and without anti-dsDNA. The authors consider that the induction of autoantibodies may interfere with the response to anti-TNF- $\alpha$ therapy in a short and initial period of time. Long-term follow-up data are lacking to say whether that influence will disappear consistently over the long run, as they observed after 12 months of therapy. However, they can state that, a priori, seroconversion should not lead to treatment suspension because of concerns about loss of efficacy.

Disclosure of Interests: None declared

DOI: 10.1136/annrheumdis-2021-eular.1287

\section{POS0915 SUSTAINABILITY OF IXEKIZUMAB RESPONSE AT THE INDIVIDUAL PATIENT LEVEL OVER TIME IN RADIOGRAPHIC AXIAL SPONDYLOARTHRITIS}

S. Ramiro $^{1}$, R. Bolce ${ }^{2}$, D. Sandoval ${ }^{2}$, A. Kronbergs ${ }^{2}$, S. Y. Park ${ }^{2}$, B. Wu ${ }^{3}$, J. A. Walsh' ${ }^{4}{ }^{1}$ Leiden University Medical Center (LUMC), Department of Rheumatology, Leiden, Netherlands; ${ }^{2}$ Eli Lilly and Company, Lilly Corporate Center, Indianapolis, United States of America; ${ }^{3}$ IQVIA RDS Canada ULC, QC Canada, Kirkland, Canada; ${ }^{4}$ University of Utah, Division of Rheumatology and the Department of Dermatology, Salt Lake City, United States of America

Background: Ixekizumab (IXE) has demonstrated efficacy in treating the signs and symptoms of radiographic axial spondyloarthritis ( $r$-axSpA) in patients (pts) up to week (Wk) 52 [1]. Pts may experience fluctuations in the improvements of their symptoms, which may impact their overall quality of life [2]. Providing data at the pt level is important to support consistency and sustainability of efficacy. Objectives: To analyse IXE response for sustainability at the individual pt level between Wks 16 and 52 .

Methods: COAST-V (NCT02696785) and COAST-W (NCT02696798) were two phase 3, multicentre, randomised, double-blind, placebo-controlled studies (adalimumab was the active control in COAST-V). Pts with active r-axSpA who were either biologic disease modifying anti-rheumatic drug (bDMARD) naïve (COAST-V) or, inadequate responders or intolerant to up to 2 TNF inhibitors (COAST-W) received IXE every 4 weeks (Q4W) or every 2 weeks (Q2W). Only IXE Q4W pts were included in the present analysis (approved dosage for the indication). Separate analyses were conducted on pts who achieved either endpoint; ASAS40 or ASDAS $<2.1$. The proportion (\%) of pts who achieved either ASAS40 or ASDAS $<2.1$, at Wk 16 and at each visit out to Wk 52 (total of 8 visits) was assessed. Missing data were imputed as non-response. Heatmaps were used to depict the data analysed at the individual patient level across all visits Results: In COAST-V, 81 pts enrolled in the trial were initially randomised to IXE Q4W. Of those, 48\% ( $\mathrm{N}=39)$ of pts achieved ASAS40 at Wk 16 (Figure 1), of which $59 \%(\mathrm{~N}=23)$ maintained ASAS40 at every visit afterwards. In total, $85 \%(\mathrm{~N}=33)$ of the ASAS40 achievers at Wk 16 maintained ASAS40 with some $(26 \%(\mathrm{~N}=10))$ fluctuations, between ASAS40 and ASAS20. In COAST-W, 114 pts enrolled in the trial were initially randomised to IXE Q4W. Of those, $25.4 \%(\mathrm{~N}=29)$ pts achieved ASAS40 at Wk 16, of which, 69\% ( $\mathrm{N}=20)$ maintained ASAS40 at every visit afterwards. In total, $83 \%(\mathrm{~N}=24)$, of the ASAS40 achievers at $\mathrm{Wk} 16$ maintained ASAS40 with some $(14 \%(\mathrm{~N}=4))$ fluctuations, between ASAS40 and ASAS20. Of the 81 pts initially randomised to IXE Q4W in COAST-V, 35 pts achieved low disease activity (ASDAS $<2.1$, LDA) at Wk 16. Of those, $54 \%(\mathrm{~N}=19)$ of pts maintained LDA at every visit afterwards. In total, $91 \%(\mathrm{~N}=32)$ of the ASDAS-LDA

\section{ASAS40}

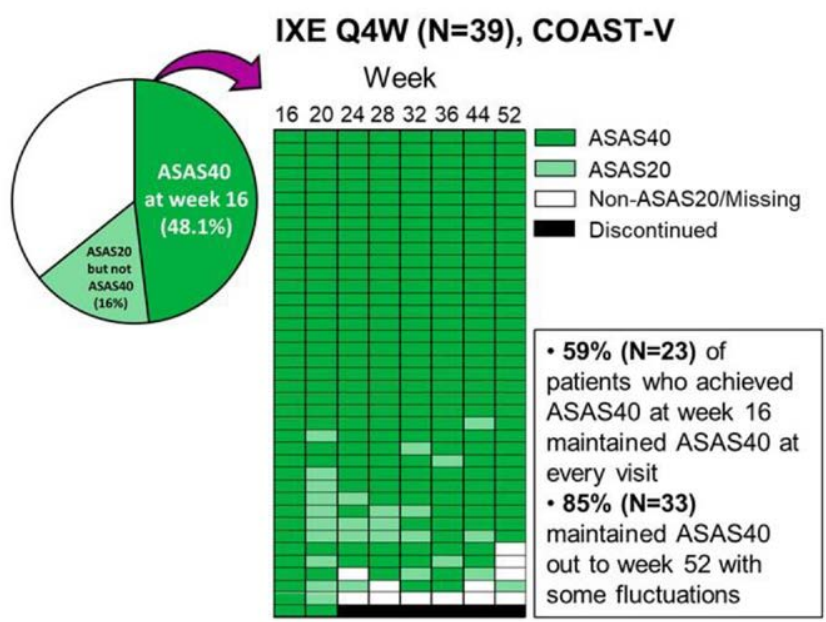

Figure 1. Heatmap diagram depicting the sustained effect of IXE over time at the pt level in pts with r-axSpA from COAST-V. Each row corresponds to an individual ASAS40 responder at Wk 16. 